Research Article

\title{
Finite Element Simulation of NiTiNb Shape Memory Alloy Pipe-Joint Subjected to Coupled Transformation and Plastic Deformation
}

\author{
Xiang Chen $\mathbb{D},{ }^{1,2}$ Bin Chen, ${ }^{1,3}$ Xianghe Peng $\mathbb{D},{ }^{1}$ Xiaoqing Jin, ${ }^{1}$ Ying Ma $\mathbb{D},{ }^{2}$ Yang Zhao, ${ }^{2}$ \\ and Hengwei Zheng $\mathbb{1}^{4}$ \\ ${ }^{1}$ The State Key Laboratory of Mechanical Transmissions, Chongqing University, Chongqing, China \\ ${ }^{2}$ Institute of Advanced Manufacturing Engineering, Chongqing University of Posts and Telecommunications, Chongqing, China \\ ${ }^{3}$ Creec Chongqing Survey and Design Institute Co., Ltd., Chongqing, China \\ ${ }^{4}$ Department of Mechanics, Chongqing University of Science \& Technology, Chongqing 401331, China
}

Correspondence should be addressed to Xianghe Peng; xhpeng@cqu.edu.cn

Received 14 June 2019; Revised 3 April 2020; Accepted 13 April 2020; Published 16 July 2020

Academic Editor: Gianfranco Palumbo

Copyright (C) 2020 Xiang Chen et al. This is an open access article distributed under the Creative Commons Attribution License, which permits unrestricted use, distribution, and reproduction in any medium, provided the original work is properly cited.

The assembling process of $\mathrm{Ni}_{47} \mathrm{Ti}_{44} \mathrm{Nb}_{9}$ alloy pipe joints considering the phase transformation and plasticity was numerically simulated for the first time with a developed constitutive model. The simulated process was based on the experimental material parameters, which were determined with the experimental tensile results of $\mathrm{Ni}_{47} \mathrm{Ti}_{44} \mathrm{Nb}_{9}$ shape memory alloy (SMA) and steel bars. The results showed that, after assembly, the Mises stress distributed uniformly along the longitudinal direction of the $\mathrm{NiTiNb}$ joint, but nonuniformly along the radial direction. The maximum $\sigma_{\mathrm{eq}}$ does not appear at the inner wall of the joints due to the coupling effect of the plastic deformation and the recoverable transformation. The contact pressure distributed uniformly along the circumferential direction, but nonuniformly along the longitudinal direction. The sizes of the SMA joint and the pipe should be properly matched to ensure contact during the stage of the rapid reverse phase transformation to obtain stable connection performance. The pull-out force was also computed, and the results were in good agreement with the experimental results. The results obtained can provide available information for the optimization of the design parameters of the high-performance SMA pipe-joint, such as inner diameter and assembly clearance.

\section{Introduction}

Due to their two unique properties, the shape memory effect (SME), and pseudoelasticity (PE), the shape memory alloy (SMA) has drawn significant attention in a broad range of commercial applications, such as automotive, aerospace, robotics, and biomedical domains $[1,2]$. The pipe-joint is manufactured with SMA even widely used as the oil pipe connection in aircraft [3]. Among the existing SMAs, NiTi binary alloy exhibits excellent mechanical properties and good SME (with about $8 \%$ recoverable strain). While the NiTi SMA pipe-joint should be stored and transported in liquid nitrogen to avoid the unexpected recovery of the predeformation, in contrast, NiTiNb SMA exhibits a much larger transformation temperature hysteresis $\left(\sim 150^{\circ} \mathrm{C}\right)$ compared with conventional NiTi binary alloy $\left(\sim 30^{\circ} \mathrm{C}\right)$ [4], and the pipe joints made of NiTiNb alloys can be stored and transported at room temperature, which is greatly convenient for engineering applications.

To date, the literature referring to experiments and numerical simulations of NiTiNb SMA is quite limited. Zhang et al. [5] analyzed the constitutional phases of $\mathrm{Ni}_{47} \mathrm{Ti}_{44} \mathrm{Nb}_{9}$ with a scanning electron microscope and found that it is composed of three phases: TiNi matrix, $\beta-\mathrm{Nb}$ particles, which are softer than the TiNi matrix and can easily be deformed plastically, and compound $\mathrm{Ti} 3(\mathrm{Ni}, \mathrm{Nb}) 2$. Recently, Shu et al. investigated the Nb solution influencing the phase transformation temperature and found that the 
increase of Ms is attributed to the micromechanism of $\mathrm{Nb}$ solution into NiTi alloy [6]. Jiang et al. [7] also investigated the influence of $\mathrm{Nb}$ addition on phase transformation, microstructure, and mechanical properties of equiatomic NiTi SMA. They found the Nb addition has a slight influence on the transformation hysteresis. It can be attributed to that the NiTiNb SMA is not subjected to plastic deformation and the $\beta$ - Nb precipitate phase is unable to relax the elastic strain energy in martensitic interfaces. Chen et al. investigated the thermomechanical behavior of $\mathrm{Ni}_{47} \mathrm{Ti}_{44} \mathrm{Nb}_{9}$ (at.\%) SMA under different thermomechanical loading histories. Their experimental results show that the equivalent stress-strain behavior and the activated martensite variants depend strongly on the thermomechanical loading history [8]. Jiang et al. found that severe plastic deformation based on equal channel angular pressing plays an important role in enhancing the transformation hysteresis of $\mathrm{Ni}_{47} \mathrm{Ti}_{44} \mathrm{Nb}_{9}$ (at.\%) SMA [9]. The effects of prestrain and heat treatment on shape recovery stress and phase transformation temperature were experimentally investigated by Uchida et al. [10], wherein NiTiNb SMAs with various $\mathrm{Nb}$ content $(6,9$, and $12 \mathrm{~mol} \%$ ). The recovery stresses of NiTiNb alloys increase with the increase of prestrain and decrease after reaching the maximum recovery stress of around 450 to $500 \mathrm{MPa}$ at about 9\% prestrain. The effect of low Nb content (3.5 at.\%, 4.5 at.\%, 5.0 at.\%) on the mechanical properties of NiTiNb SMA has been investigated in detail by differential scanning calorimetry (DSC), tensile test, and scanning electron microscope (SEM) [11]. The experimental results show that with the increase of $\mathrm{Nb}$ content, the yield strength increases, and the elongation decreases gradually.

Recently, the metal joint industry is developing rapidly, including the product method [12], the combination approach [13], and new processing technology [14]. While the literature on SMA joints is relatively few, Tabesh et al. [15] designed a commercial NiTiNb coupler and tested it. They found that the thermal-induced contact pressure depends on several factors such as the dimensions and properties of the coupler-pipe system. They also developed coupler-ring finite element model with the constitutive equations established by Machado and Lagoudas [16]. This 3-dimensional phenomenological constitutive model focuses on the generation and recovery of transformation strains that occur because of martensitic transformation. The Gibbs energy is selected to be the thermodynamic potential in the constitutive model. The comparison and evaluation of the shape memory effect under different expansion temperatures and expansion strains were performed. It is reported that the largest strain for the NiTiNb SMA joints appears on the inner wall, and there exists a larger strain gradient along the axis [17]. Piotrowski and his coworker did excellent studies on the constitutive model of NiTiNb SMA and the application to tightening rings $[18,19]$. In their research studies, the $\mathrm{Nb}$ precipitates were considered as elastic-plastic inclusions embedded in the NiTi matrix. Heating can induce inverse transformation, and the SMA rings will be tightened automatically on the pipes. The variation of the contact pressure against temperature was measured and compared with the numerical results [18]. In addition, the effects of the ridge thickness, the distance between ridge and ring extremity, and the geometrical defects were simulated [19]. However, the constitutive models adopted in the above excellent work did not consider the plasticity of SMA and its effects, while during predeformation, plastic deformation involved in the NiTi matrix can obviously increase the transformation hysteresis temperature [20]. The plastic deformation plays an important role in thermomechanical behavior during the following assembly process and should be taken into account in the analysis. Great efforts were made in the constitutive model of SMAs [21-23]; however, due to the complex microstructure of NiTiNb SMA, few models can accurately describe its specific behaviors. Chen et al. [24] developed a three-dimensional phenomenological model, which is coupled with the transformation and plastic behavior of SMA. In the model, the strain is separated into elastic, thermal, transformational, and plastic strains, and two yield functions are adopted to describe the transformation and plastic deformation, respectively. The model can well describe the behavior of the SMAs subjected to complex thermomechanical loading paths, including shape memory effect, pseudoelasticity, coupled transformation and plastic deformation, and the effect of plastic deformation on the inverse transformation.

In the present study, the assembling process of $\mathrm{Ni}_{47} \mathrm{Ti}_{44} \mathrm{Nb}_{9}$ alloy pipe joints is simulated with the threedimensional SMA model developed by Chen et al. [24]. Two types of the pipe-joint assembly processes are considered: (1) the same steel pipes but the SMA joints are of different outer diameters (the inner diameters of the SMA joints are the same); (2) the same SMA joints but the steel pipes are of different outer diameters (the inner diameters of the steel pipes are the same). The main content of this article contains two parts. First, the material parameters of NiTiNb joints and steel pipes are determined with an experiment, based on which the finite element (FE) model is built. Second, the distribution of Mises stress, contact pressure, and other thermal-mechanical quantities in the pipe-joint systems is analyzed and discussed.

\section{Experiment and Finite Element Model}

2.1. Material Tested. The transformation temperatures of the $\mathrm{Ni}_{47} \mathrm{Ti}_{44} \mathrm{Nb}_{9}$ alloy used in the present work were obtained by DSC [8], as shown in Figure 1. The initial four transformation temperatures are determined from the curves, as summarized in Table 1. It was reported that there is a characteristic deformation temperature $\left(\mathrm{Ms}+30^{\circ} \mathrm{C}\right)$ and a maximum tensile strain (about 16\%), at which the transformation hysteresis can effectively increase and the strain recovery ratio remains significantly high [25]. In general, $\mathrm{NiTiNb}$ joints are expanded at $\mathrm{Ms}+30^{\circ} \mathrm{C}$ before assembly, and the circumferential tensile stress is the main stress formed during this process. The corresponding tensile strain can reach $\varepsilon=16 \%$. In this study, $\mathrm{Ni}_{47} \mathrm{Ti}_{44} \mathrm{Nb}_{9}$ alloy was used as the pipe-joint material, and the stress-strain curve (with $\varepsilon_{\max }=0.16$ ) during tensile deformation at $-60^{\circ} \mathrm{C}$ and subsequent heating recovery were used to determine material parameters. 


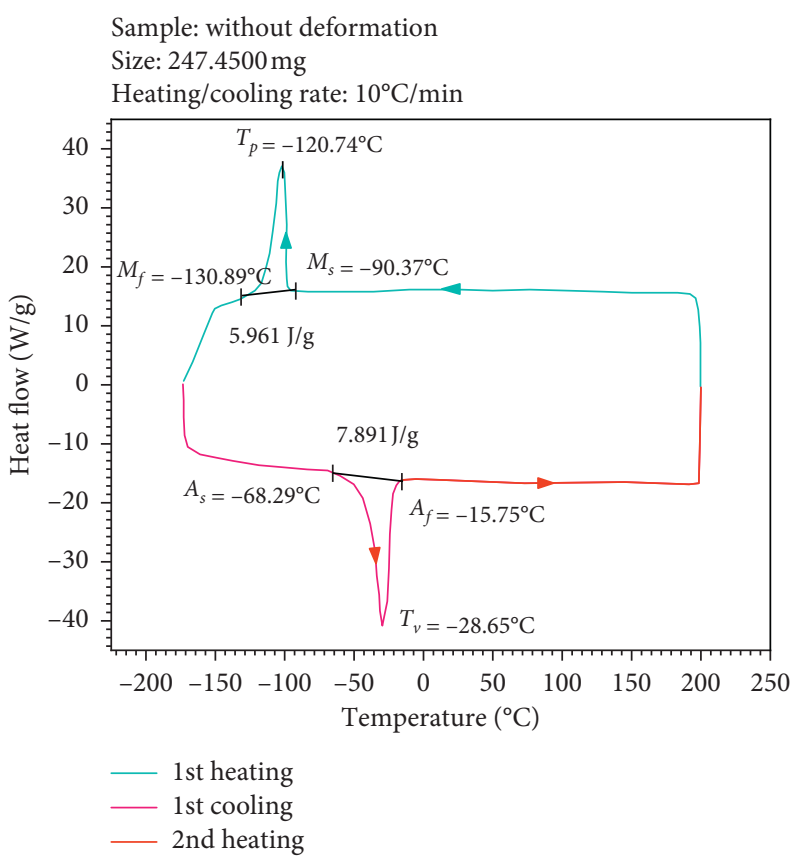

Figure 1: The DSC curves of the initial NiTiNb SMA [8] before predeformation.

Table 1: Material parameters of the NiTiNb and the steel.

\begin{tabular}{|c|c|c|c|c|c|c|c|}
\hline \multicolumn{8}{|c|}{ NiTiNb parameters } \\
\hline \multicolumn{8}{|c|}{ Transformation temperature $\left({ }^{\circ} \mathrm{C}\right)$} \\
\hline Martensite & & \multirow{2}{*}{\multicolumn{2}{|c|}{$\begin{array}{c}\text { Martensite start } \\
M_{s}=-90.37^{\circ} \mathrm{C}\end{array}$}} & \multirow{2}{*}{\multicolumn{2}{|c|}{$\begin{array}{c}\text { Austenite start } \\
A_{s}=-68.29^{\circ} \mathrm{C}\end{array}$}} & \multirow{2}{*}{\multicolumn{2}{|c|}{$\begin{array}{c}\text { Austenite finish } \\
A_{f}=-15.75^{\circ} \mathrm{C}\end{array}$}} \\
\hline$M_{f}=-130.8$ & & & & & & & \\
\hline \multicolumn{8}{|c|}{ Material constants of joint } \\
\hline$E(\mathrm{GPa})$ & $v$ & $B\left(\mathrm{MPa} /{ }^{\circ} \mathrm{C}\right)$ & $M_{0}\left({ }^{\circ} \mathrm{C}\right)$ & $C_{t}(\mathrm{MPa})$ & $C_{p}(\mathrm{MPa})$ & $\xi$ & $\zeta$ \\
\hline 45000 & 0.3 & 4 & -60 & 300 & 300 & 80 & 15 \\
\hline$Y_{0}(\mathrm{MPa})$ & $R_{0}(\mathrm{MPa})$ & $Q_{0}(\mathrm{MPa})$ & $\sigma_{s}^{t}(\mathrm{MPa})$ & $\sigma_{s}^{p}(\mathrm{MPa})$ & $Q_{1}(\mathrm{MPa})$ & $\varepsilon \mathrm{L}$ & $\theta\left(1 /{ }^{\circ} \mathrm{C}\right)$ \\
\hline 0 & 550 & 120 & 180 & 220 & 300 & 0.08 & $10-5$ \\
\hline \multicolumn{8}{|c|}{ Steel parameters } \\
\hline Material & Elastic modulus & \multicolumn{2}{|c|}{ Yield strength } & Ultimate strength & \multirow{2}{*}{\multicolumn{2}{|c|}{$\begin{array}{c}\text { Coefficient of } \\
\text { thermal expansion } \\
\alpha=1.2 \times 10^{-5}\left(1 /{ }^{\circ} \mathrm{C}\right)\end{array}$}} & Poisson's ratio \\
\hline HR-2 steel & $E=205 \mathrm{GPa}$ & $\sigma_{s}=4$ & $\mathrm{IPa}$ & $\sigma_{\mathrm{b}}=720 \mathrm{MPa}$ & & & $\nu=0.28$ \\
\hline
\end{tabular}

Material composition and the size of test samples are similar to the literature [4], as shown in Figures 2(a) and 2(b). The uniaxial tensile tests of $\mathrm{Ni}_{47} \mathrm{Ti}_{44} \mathrm{Nb}_{9}$ alloy under $-60^{\circ} \mathrm{C}$ were conducted on the MTS-858 electrohydraulic servo system, with axial loading capacity $\pm 15 \mathrm{kN}$ and torque $\pm 100 \mathrm{~N}$-m (see Figure 2(c)). The stain-control mode was adopted and the loading/unloading rates were chosen as $\pm 1.3 \times 10^{4} \mathrm{~s}^{-1}$. As shown in Figure 2(c), the Epsilon (3542-010M-025-LHT) extensometer, with an accuracy grade of 0.5 (ISO9513) and temperature range of $-270^{\circ} \mathrm{C}$ to $200^{\circ} \mathrm{C}$, was used to measure the tensile strain. The red box is the installation diagram. A GDW-50 temperature chamber was used to provide the testing temperature ranging from $-70^{\circ} \mathrm{C}$ to $150^{\circ} \mathrm{C}$, with fluctuation of $\pm 0.5^{\circ} \mathrm{C}$ and nonuniformity of $\pm 2^{\circ} \mathrm{C}$ (see Figure 2(d)). The heating/ cooling rates were controlled $\pm 2^{\circ} \mathrm{C} / \mathrm{min}$ to avoid the inhomogeneous distribution of temperature within the testing specimen.
The stress-strain $\left(\sigma_{33}-\varepsilon_{33}\right)$ curve of loading and unloading is shown in Figure 3. The tests were repeated three times with virtually the same results. This repeating practice was emphasized by Krahmer et al. [26] and was used to check the stability of material response. A typical "elasticitytransformation-strengthen" loading curve can be found and during unloading, no obvious recoverable strain occurred. The following constraint heating result is shown in Figure 4(a) and the stress-free heating result is shown in Figure 4(b). For the case of Figure 4(a), during the heating process, the $\varepsilon_{33}$ was kept unchanged by the MTS machine. One can find that the stress $\sigma_{33}$ decreases with the increase of temperature (T) from $-60^{\circ} \mathrm{C}$ to about $50^{\circ} \mathrm{C}$; this is due to thermal expansion of the alloy. Heating leads to a tendency of elongation along the sample's axial direction, while $\varepsilon_{33}$ was kept unchanged by the MTS machine at this time. Thus, the compressure occurred and $\sigma_{33}$ decreased. When the temperature was heated to $50^{\circ} \mathrm{C}$, the stress $\sigma_{33}$ increased with the increase of temperature $(T)$. It 


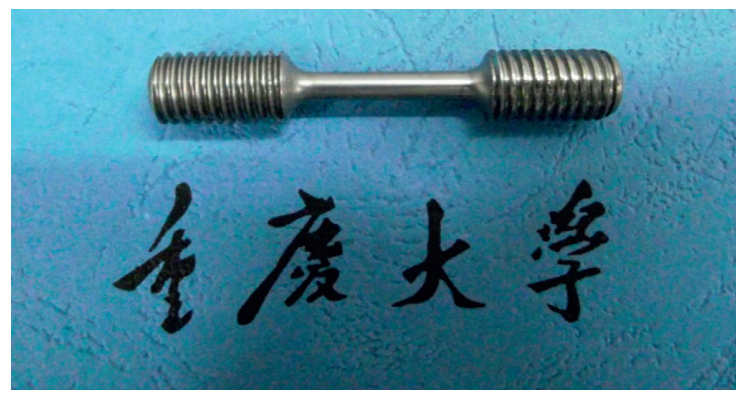

(a)

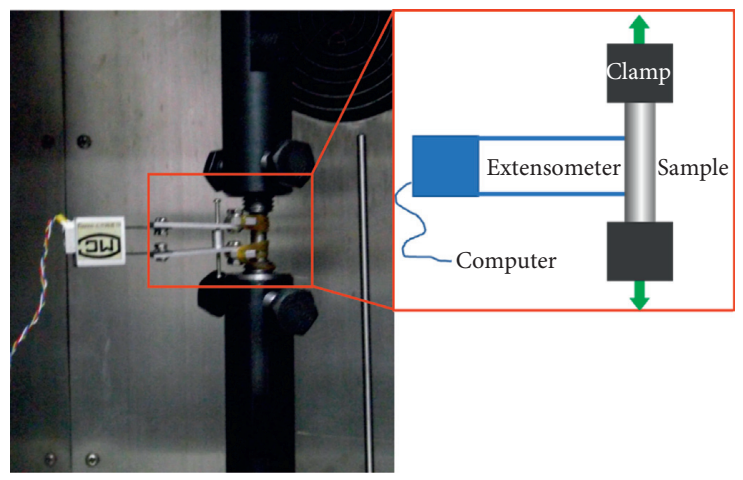

(c)

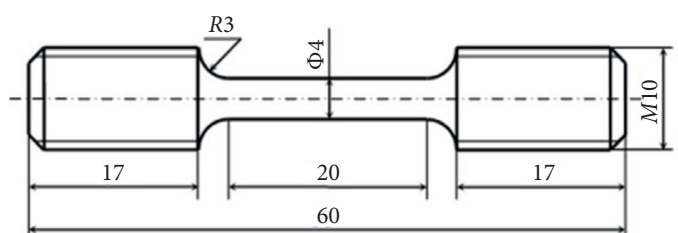

(b)

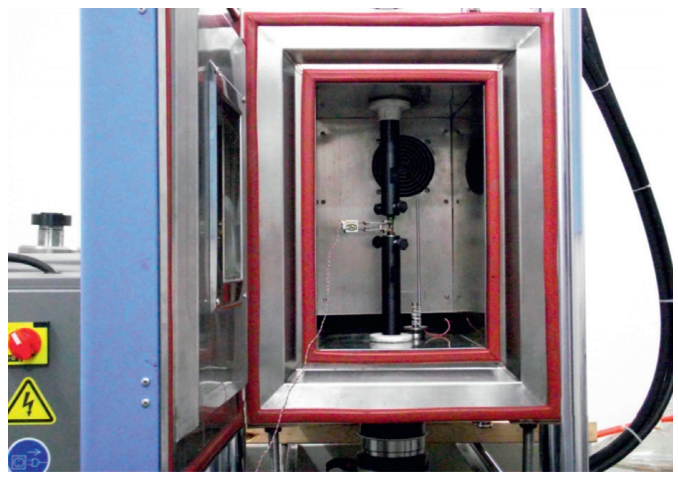

(d)

Figure 2: The experimental test: (a) the NiTiNb sample, (b) the size of the sample (mm), (c) the experimental clamping state, and (d) the temperature environment.

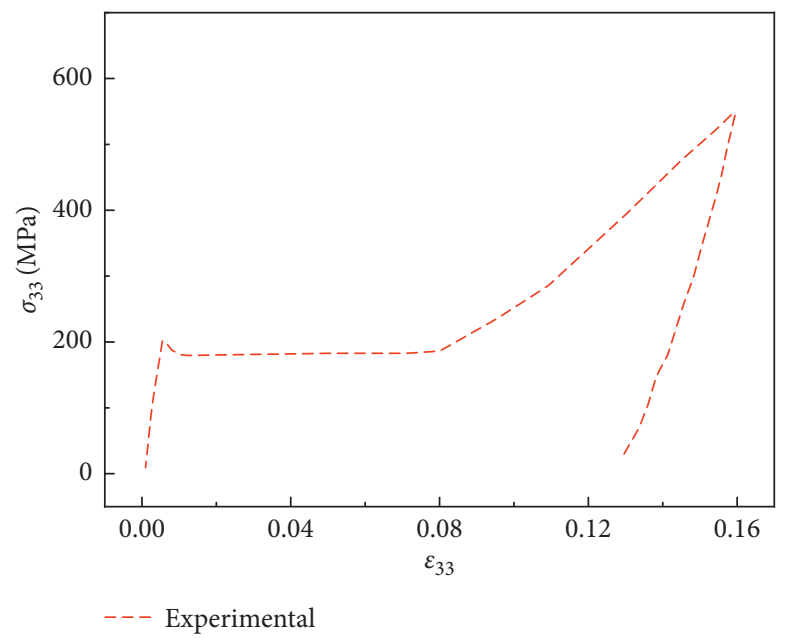

Figure 3: Experimental $\sigma-\varepsilon$ tensile curve of NiTiNb SMA sample at $-60^{\circ} \mathrm{C}$.

can be attributed to the reverse phase transformation that occurred in the heating process and the sample tended to shorten. Similarly, by the constraint of collets, stretching stress appeared and $\sigma_{33}$ increased. For the case of Figure 4(b), it can be found that the residual strain decreases slowly before the temperature is around $50^{\circ} \mathrm{C}$. Between $50^{\circ} \mathrm{C}$ to $75^{\circ} \mathrm{C}$, the residual strain decreases rapidly, which is attributed to the reverse phase transformation. When the temperature exceeds $75^{\circ} \mathrm{C}$, the rate of decrease goes back to the initial level. Comparing with Figure 1, one can find that the predeformation increases the As from $-68.29^{\circ} \mathrm{C}$ to about $50^{\circ} \mathrm{C}$.
The mechanical property of the steel pipe to be connected was also tested at room temperature, as shown in Figure 5. In the initial stage of uniaxial tension, the steel exhibited elastic deformation, while the stress raised to about $450 \mathrm{MPa}$; obvious plastic deformation can be found. The steel exhibited an elastoplastic feature of linear strain-hardening.

2.2. NiTiNb Constitutive Model. The constitutive model developed by Chen et al. [24] was used, in which the effects of plastic deformation were considered. As the effects of plastic deformation of $\mathrm{Nb}$ phase and martensite on the 


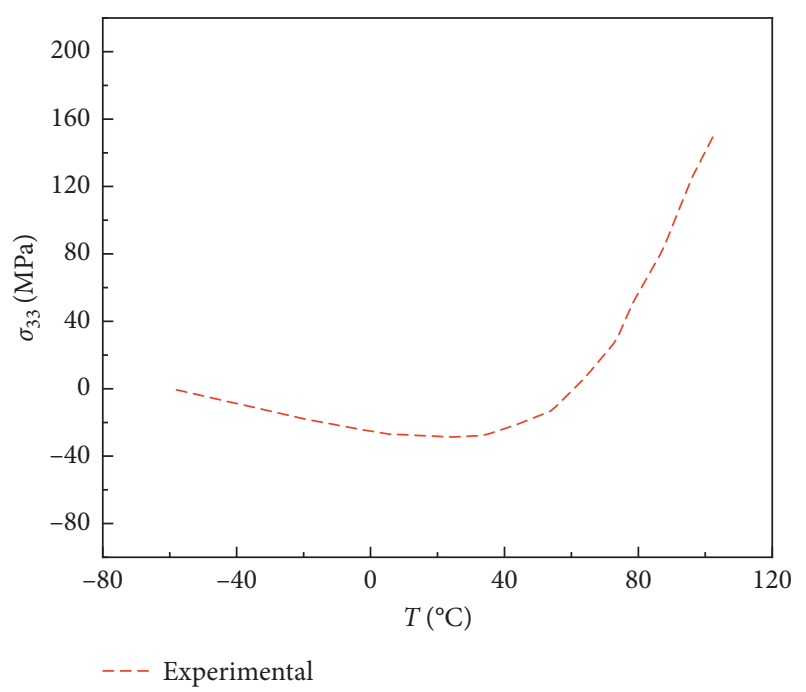

(a)

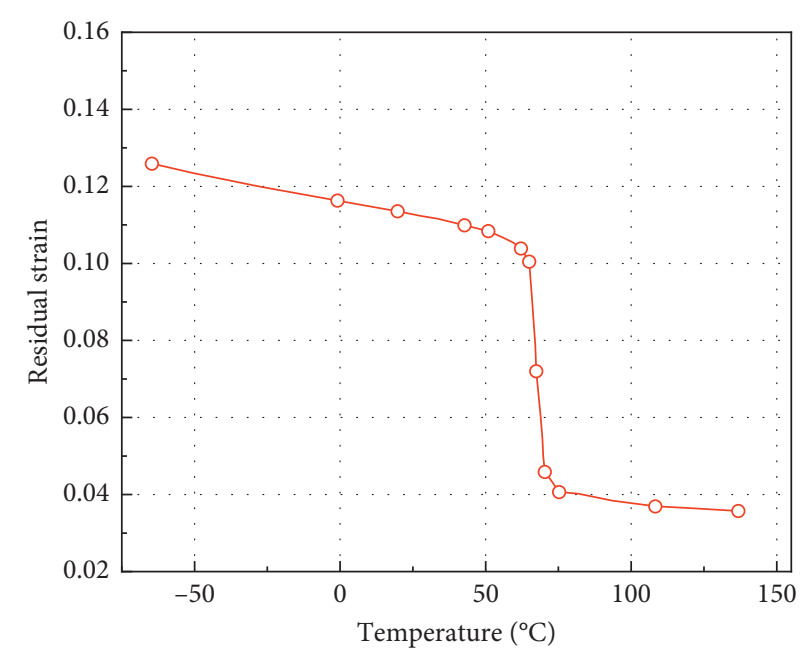

(b)

FIgURE 4: Experimental temperature recovery characteristic of (a) constraint heating and (b) stress-free heating.

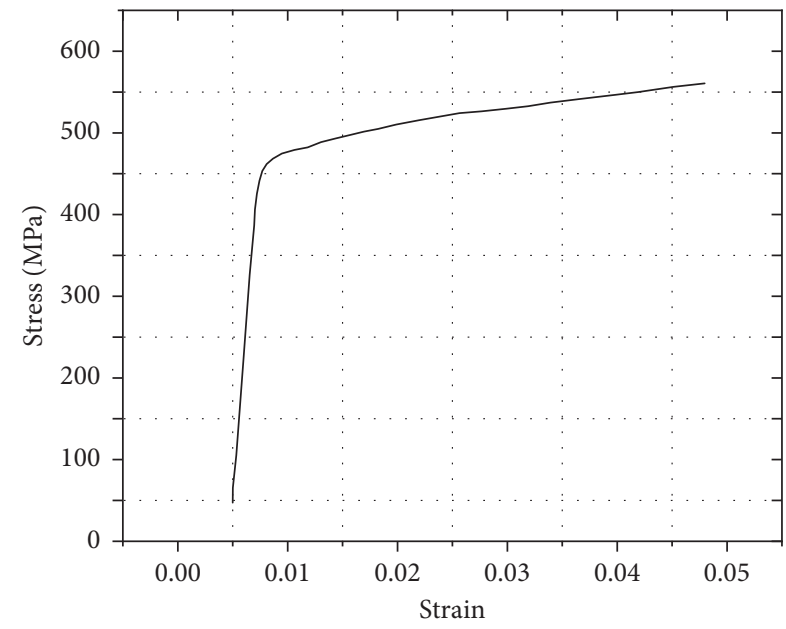

Figure 5: Tensile stress-strain curve of steel pipe material.

reverse phase transformation temperature are similar, we make no distinction between the two plasticities and make them equivalent to a unified plastic evolution equation. The brief introduction of the model is described as follows.

The model assumes that the free energy $\Phi$ is the function of elastic strain $\boldsymbol{\varepsilon}^{\mathrm{e}}$, transformation strain $\boldsymbol{\varepsilon}^{\mathrm{t}}$, tensor $\boldsymbol{\alpha}$ and accumulated plastic strain $p$ associated with plasticity-induced hardening, and temperature $\mathrm{T}$ :

$$
\Phi=\Phi\left(\boldsymbol{\varepsilon}^{\mathrm{e}}, \boldsymbol{\varepsilon}^{\mathrm{t}}, \boldsymbol{\alpha}, p, T\right),
$$

where

$$
\boldsymbol{\varepsilon}^{\mathrm{e}}=\boldsymbol{\varepsilon}-\boldsymbol{\varepsilon}^{\mathrm{t}}-\boldsymbol{\varepsilon}^{\mathrm{p}}-\boldsymbol{\varepsilon}^{\theta},
$$

where $\varepsilon$ and $\varepsilon^{\mathrm{p}}$ are the total strain and plastic strain. Thermal strain $\varepsilon^{\theta}$ can be expressed as follows:

$$
\boldsymbol{\varepsilon}^{\theta}=\theta\left(T-T_{0}\right),
$$

in which $\theta$ is the coefficient tensor of thermal expansion and $T_{0}$ is a reference temperature. Considering the interaction of transformation and plasticity, $\Phi$ can be further expressed as follows:

$$
\begin{aligned}
\Phi\left(\boldsymbol{\varepsilon}^{\mathrm{e}}, \boldsymbol{\varepsilon}^{\mathrm{t}}, \boldsymbol{\alpha}, p, T\right)= & \Phi^{\mathrm{e}}\left(\boldsymbol{\varepsilon}^{\mathrm{e}}, T\right)+\Phi^{\mathrm{t}}\left(\boldsymbol{\varepsilon}^{\mathrm{t}}, T\right)+\Phi^{\mathrm{p}}(\alpha, p, T) \\
& +\Phi^{\theta}(T)+\Phi^{c}\left(\boldsymbol{\varepsilon}^{t}, p\right),
\end{aligned}
$$

where

$$
\begin{aligned}
\Phi^{\mathrm{e}}\left(\boldsymbol{\varepsilon}^{\mathrm{e}}, T\right) & =\frac{1}{2 \rho} \boldsymbol{\varepsilon}^{\mathrm{e}}: C: \boldsymbol{\varepsilon}^{\mathrm{e}}, \\
\Phi^{\mathrm{t}}\left(\boldsymbol{\varepsilon}^{\mathrm{t}}, T\right) & =\frac{1}{3 \rho} C^{\mathrm{t}} \boldsymbol{\varepsilon}^{\mathrm{t}}: \boldsymbol{\varepsilon}^{\mathrm{t}}+\frac{1}{\rho} \tau_{M}(T)\left\|\boldsymbol{\varepsilon}^{\mathrm{t}}\right\|+\frac{1}{\rho} \Gamma\left(\boldsymbol{\varepsilon}^{\mathrm{t}}\right), \\
\Phi^{\mathrm{p}}(\boldsymbol{\alpha}, p, T) & =\frac{1}{3 \rho} C^{\mathrm{p}} \boldsymbol{\alpha}: \boldsymbol{\alpha}+\frac{1}{\rho} Y(p), \\
\Phi^{\theta}(T) & =c_{\mathrm{v}}\left[\left(T-T_{0}\right)-T \ln \left(\frac{T}{T_{0}}\right)\right], \\
\Phi^{\mathrm{c}}\left(\boldsymbol{\varepsilon}^{\mathrm{t}}, p\right) & =-\frac{1}{\rho} Q(p)\left\|\boldsymbol{\varepsilon}^{\mathrm{t}}\right\|,
\end{aligned}
$$

where $C$ is the standard isotropic elasticity tensor, $C_{\mathrm{p}}$ and $C_{\mathrm{t}}$ the are material parameters, and $\rho$ and $C_{\mathrm{v}}$ are the density and specific heat, respectively, which are assumed invariant during phase transformation and plastic region. $\tau_{M}(T)$ can be defined as follows:

$$
\tau_{M}(T)= \begin{cases}B\left(T-M_{0}\right), & T>M_{0}, \\ 0, & T \leq M_{0},\end{cases}
$$

where $B$ represents the sensitivity of the stress with respect to temperature $T$ and $M_{0}$ is the reference temperature below 
which no twinned martensite is observed [27], and it is usually regarded as the martensite transformation finished temperature $M_{f} .\left\|\varepsilon^{t}\right\|$ denotes the Euclidean norm of $\varepsilon^{t}$ of rank two. The function $\Gamma\left(\varepsilon^{t}\right)$ is similar to the additional indicator function adopted by Frémond and Nedjar [28], which satisfies the following phenomenological physical constraints:

$$
\begin{aligned}
\gamma & \geq 0, \\
\left\|\varepsilon^{t}\right\|-\varepsilon_{L} & \leq 0, \\
\Gamma\left(\varepsilon^{t}\right)=\gamma\left(\left\|\varepsilon^{t}\right\|-\varepsilon_{L}\right) & =0,
\end{aligned}
$$

in which $\gamma$ is the Lagrange multiplier and $\varepsilon_{L}$ is the critical maximal value of phase transformation under saturated state; it is a given constant in the process of calculation. The effects of plastic deformation on phase transformation is considered by $Q(p)$, and it can be defined as follows:

$$
Q(p)=Q_{0}(1-\exp (-\xi p))
$$

where $Q_{0}$ and $\xi$ are the material parameters. The function $Q(p)$ is based on the fact that there is a close relationship between the inverse transformation start temperature As and the permanent strain [20]. Such a function is used to describe the phenomenon that the influence of plastic deformation on the phase transformation will reach a certain limit. The drag stress of plastic is defined as follows:

$$
\begin{aligned}
R & =\rho \frac{\partial \Phi}{\partial p}=Y^{\prime}(p)-Q^{\prime}[p]\left\|\varepsilon^{\mathrm{t}}\right\| \\
& =R_{0}(1-\exp (-\zeta p))-Y_{0} \exp (-\xi p)\left\|\varepsilon^{\mathrm{t}}\right\|,
\end{aligned}
$$

in which $R_{0}, \zeta$, and $Y_{0}$ are the material parameters.

The above constitutive equations can be rewritten in incremental ones and calculated via the return mapping scheme (an implicit algorithm). The corresponding user material subroutine UMAT was developed and embedded into FE code ABAQUS, with which the installation process of NiTiNb pipe joints can be simulated. A detailed model and algorithm can be found in [24].

2.3. Parameters Identification. Based on the experimental results, the parameters of the NiTiNb SMA constitutive model can be identified. The four phase transition temperatures are determined from the DSC curves. The elasticity modulus $E$, the starting stress of martensite transformation $\left(\sigma_{s}^{t}\right)$ and plasticity $\left(\sigma_{s}^{p}\right)$, and the maximum strain of martensite transformation $\left(\varepsilon_{L}\right)$ can be determined from the uniaxial tension. The $B, R_{0}$, and $Q_{0}$ can be determined from the constrained heating test. The relative parameters of the $\mathrm{Ni}_{47} \mathrm{Ti}_{44} \mathrm{Nb}_{9}$ alloy and the steel are summarized in Table 1.

2.4. Finite Element Model. The commercially available finite element code ABAQUS ${ }^{\circledR}$ is used for simulation. The UMAT subroutine based on the constitutive model is developed and embedded in ABAQUS. A kind of aeronautics oil pipe joints is simulated, which is $3 \mathrm{~mm}$ in inner diameter and $11 \mathrm{~mm}$ in length. As the contact force mainly affects the contact area between the joint and pipe, to reduce computation time, we take the total length of two pipes as $13 \mathrm{~mm}$. To compare the effect of the thickness and assembly interference on the mechanical property during assembling process, two groups of pipe-joint systems were simulated: (1) steel pipes of same size and the NiTiNb joints with the same inner diameter but different external diameters; (2) NiTiNb joints of the same size and steel pipes with the same inner diameter but different external diameters. The specific sizes of the pipe-joint and steel are listed in Table 2.

In general, we expand the NiTiNb joint to $\varepsilon=16 \%$ at $T=-60^{\circ} \mathrm{C}$, heat the temperature to room temperature, and then assemble the pipes and joint, followed by heating the joint to a prescribed high temperature (e.g., $100^{\circ} \mathrm{C}$ ). Whole assembling process can easily be resolved into the five steps, as shown in Table 3.

Considering the symmetry of the system, we only calculated a quarter of the system using an axisymmetric model, as shown in Table 3. In the FE model of the pipe-joint system, 8-node linear brick elements were adopted to mesh the NiTiNb joint, and 8-node linear brick reduced integration elements were adopted to mesh the steel pipe. Since contact behavior between the outer surface of the steel pipe and the inner surface of the NiTiNb joint is surface contact forms during the assembly and drawing process, the "penalty" contact pair form of tangential behavior is added. As the elastic modulus of the steel pipe is greater than that of the NiTiNb joint, the outer surface of the steel pipe is defined as the active contact surface, while the inner surface of the $\mathrm{NiTiNb}$ joint is defined as the passive contact surface, with a friction coefficient of 0.2 . To avoid the nonconvergence caused by rapid strain recovery in the NiTiNb joint during heating, the maximum time increment is set as 0.001 (the step duration is 1.0).

\section{Results and Discussion}

3.1. Model Checking. The uniaxial tension at $-60^{\circ} \mathrm{C}$ and subsequent constrained heating recovery are simulated firstly to verify the correctness of the constitutive model. The results of the calculation are compared with experimental results, as shown in Figures 6 and 7. The tensile stress-strain $\left(\sigma_{33}-\varepsilon_{33}\right)$ curve calculated with the constitutive model agrees reasonably with the experimental results. However, since the phenomenological model in this study does not consider the local instability and softening of the material caused by the martensite nucleus, the initial stress drop of the phase transformation cannot be described. For the plastic deformation stage, the von Mises stress of the finite element simulation results is slightly larger than the experimental results. As indicated above, the yield function defined in the present work is a convex function. Therefore, the numerical simulation results after entering the plastic deformation stage are convex compared with the experimental results. The measured residual strain after unloading is less than that of numerical simulation, because the phenomenological model does not consider the local evolution characteristics of material properties during unloading, such as the local reverse phase 
TABLE 2: Geometrical size of NiTiNb joints and steel pipes.

\begin{tabular}{|c|c|c|c|c|c|}
\hline \multicolumn{6}{|c|}{ Geometrical size of NiTiNb joints } \\
\hline & \multicolumn{2}{|c|}{ Joint $1 \#(J 1)$} & Joint 2\# (J2) & \multicolumn{2}{|c|}{ Joint 3\# (J3) } \\
\hline Inner diameter $(\mathrm{mm})$ & \multicolumn{2}{|c|}{3.00} & 3.00 & \multicolumn{2}{|c|}{3.00} \\
\hline Outer diameter $(\mathrm{mm})$ & & & 5.10 & \multicolumn{2}{|c|}{4.40} \\
\hline \multicolumn{6}{|c|}{ Geometrical size of steel pipes } \\
\hline & Pipe 1\# (P1) & Pipe 2\# (P1) & Pipe 3\# (P1) & Pipe 4\# (P1) & Pipe 5\# (P1) \\
\hline Inner diameter (mm) & 2.00 & 2.00 & 2.00 & 2.00 & 2.00 \\
\hline Outer diameter (mm) & 3.16 & 3.22 & 3.28 & 3.34 & 3.40 \\
\hline
\end{tabular}

TABLE 3: Assembling process and FE model.

\begin{tabular}{llll}
\hline $\begin{array}{l}\text { Analysis } \\
\text { step }\end{array}$ & Sketch map & Assembling process & FE model \\
\hline
\end{tabular}

Step I

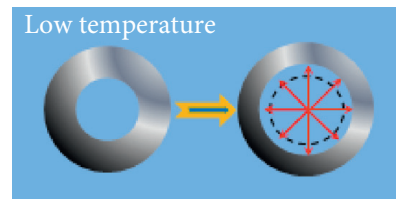

Expanding inner diameter of the joint from $3.0 \mathrm{~mm}$ to $3.48 \mathrm{~mm}$ (corresponding to the circumferential strain of about 0.16 at its inner wall) at $-60^{\circ} \mathrm{C}$.

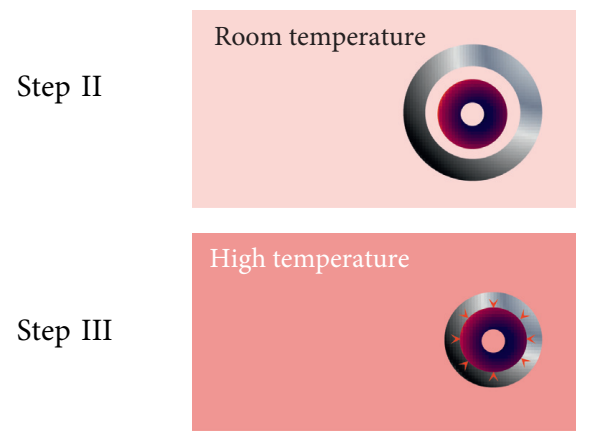

Unloading the expanding pressure, and raise the temperature to $23^{\circ} \mathrm{C}$

Insert the pipes into the joint, followed by heating the pipe-joint system to $100^{\circ} \mathrm{C}$.

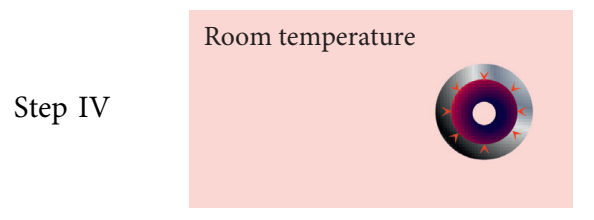

Cooling the system down to room temperature $\left(23^{\circ} \mathrm{C}\right)$. After assembly, add the following step to calculate the pull-out force.

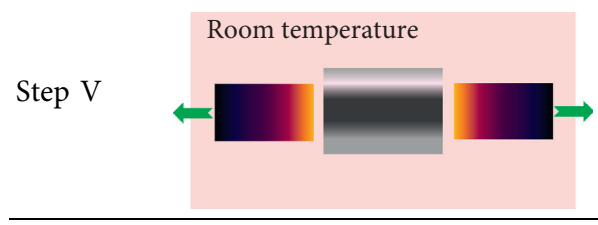

transformation and reorientation, so it shows stronger linear elasticity compared with the experimental results. However, for the engineering application of the SMA pipejoint, the above deficiencies have less impact on its service performance. The comparison between the experimental and numerical results shows that the model can well describe the main characteristics of the deformation in tension and the subsequent thermal recovery property. It indicates that the model can reasonably be used to simulate the behavior of NiTiNb SMA joints.
3.2. Distribution of Mises Stress. After assembling, the contour maps of Mises equivalent stress, $\sigma_{\text {eq }}$, in the joints J1, $\mathrm{J} 2$, and J3 connected with P3 (Table 2) are shown in Figure $8(\mathrm{a})$. It can be seen that the $\sigma_{\text {eq }}$ beyond the contact area of the pipe is very small, which implies that the effect of the assembly contact along the axis of pipe can be ignored out of the contact area. The distribution of $\sigma_{\text {eq }}$ in the contact region is quite different among the three cases, and the maximum value of $\sigma_{\text {eq }}$ decreases with the decrease of the outer diameter of the joint. Within the joint, $\sigma_{\text {eq }}$ distributes 


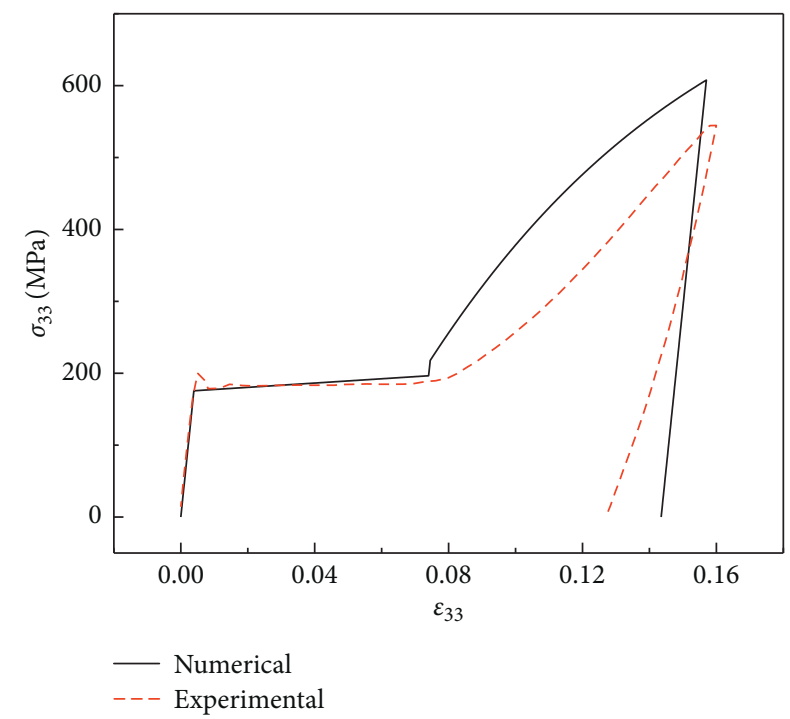

Figure 6: Experimental and simulated $\sigma-\varepsilon$ tensile curves of NiTiNb SMA sample at $-60^{\circ} \mathrm{C}$.

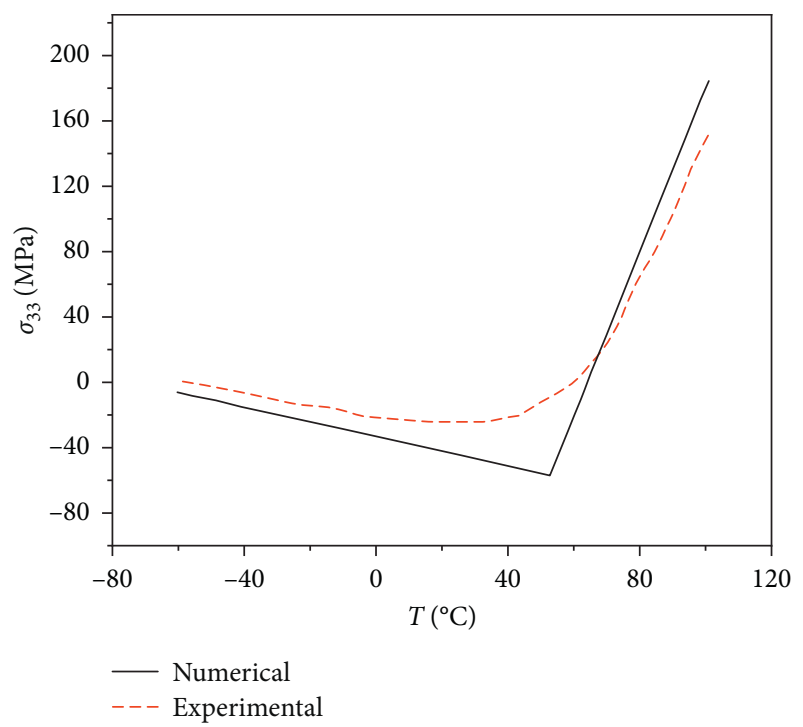

FIGURE 7: Characteristics of constraint heating compared between numerical simulation and experimental one.

uniformly along the longitudinal direction, but nonuniformly along the radial direction. To facilitate the analysis, the contour map of $\sigma_{\mathrm{eq}}$ in the cross-section of the NiTiNb joint is shown in Figure 8(b) and the variation of $\sigma_{\text {eq }}$ against the radius is shown in Figure 9. It can be found that for case J2-P3 and case J3-P3, $\sigma_{\text {eq }}$ increases monotonically from the inner wall to the outer wall, but the changes become insignificant after $\lambda R$ (the radial position) is $2.3 \mathrm{~mm}$. Thus we do not need to increase the thickness of the NiTiNb SMA joint wall unlimited. While for case J1-P3, $\sigma_{\text {eq }}$ increases firstly until $\lambda R=2.16 \mathrm{~mm}$, and then decreases. It indicates that the distribution of $\sigma_{\text {eq }}$ is closely related to the wall thickness of the joint. An obvious difference is that the maximum $\sigma_{\text {eq }}$ does not appear at the inner wall of the joints, which is different from the previous study $[18,19]$. This interesting phenomenon is closely related to the coupling effect of the plastic deformation and the recoverable transformation of the NiTiNb joint. Interfered by the external environment, the joint whose maximal equivalent stress distributed on the surface outside or inside will be easier to fail. Therefore, appropriate wall thickness and the ratio of expanding diameter should be designed. Figure 10 shows the distribution of $\sigma_{\mathrm{eq}}$ along the radial direction in the pipe. It can be seen that $\sigma_{\text {eq }}$ decreases monotonically with the increase of $\lambda R$ (from inner to outer). Taking J1-P3 as an example, $\sigma_{\text {eq }}$ decreases from $420 \mathrm{MPa}$ at the inner surface to about $300 \mathrm{MPa}$ at the outer surface. On the other hand, with the increase of wall thickness, $\sigma_{\mathrm{eq}}$ in the pipe increases from about $220 \mathrm{MPa}$ (for J3-P3) to $420 \mathrm{MPa}$ (for J1-P3). Therefore, when selecting the wall thickness of the NiTiNb SMA joint, the bearing capacity of the steel pipe should be considered to avoid the overlarge restoring force in the assembling process.

The von Mises stress, plastic deformation, and phase transformation strain distributed in the NiTiNb SMA joint at the end of different steps are analyzed. For instance, the results of the J1-P3 system are shown in Figure 11. It can be found that, in step I, the Mises stress decreases from inside to outside; the same law can also be found in plastic strain and transformation strain. In the constitutive model of $\mathrm{NiTiNb}$ SMA, when the stress is greater than $220 \mathrm{MPa}$, the material gets into the plastic deformation stage (see Figure 6). Therefore, the plastic strain is very small, and the phase transformation strain has not yet reached the critical value in the outer wall of the joint. In step II, the load is removed at $-60^{\circ} \mathrm{C}$, so the von Mises stress within the joint is very small, while the plastic strain and the phase transformation strain remain unchanged. It is reasonable because the plastic strain is irreversible and the reverse phase transition temperature is raised after the predeformation, so there is no transformation strain to recover. After heating, the transformation strain is partial recovery because the constraint from the steel pipe is existing on the joint. Thus the transformation strain cannot fully recover. It can also be found that the plastic strain keeps unchanged in the subsequent steps since it comes into being in step I. The above analysis of different variables in the SMA joint coincides with the response of NiTiNb material and deepens the understanding of the deformation characteristics of the SMA joint during the whole assembly process.

3.3. Contact Pressure Distribution. The distribution of the contact pressure $\left(\sigma_{r}\right)$ at the pipe-joint interface is shown in Figure 12. It can be found that the contact pressure distributes uniformly along the circumferential direction. However, it distributes nonuniformly along the longitudinal direction and symmetrically along the middle point. The inhomogeneous stress gradient along the longitudinal direction will bring an inhomogeneous strain on the contact surface, which may increase the surface friction between the pipe and joint. Besides, with the increase of joint thickness, the maximum contact pressure increases, and the stress concentration attenuates. To better understand the result, the longitudinal distribution of $\sigma_{r}$ within $\mathrm{J} 1, \mathrm{~J} 2$, and $\mathrm{J} 3$ is shown in Figure 13. For J3, the maximum $\sigma_{r}$ appears at the 


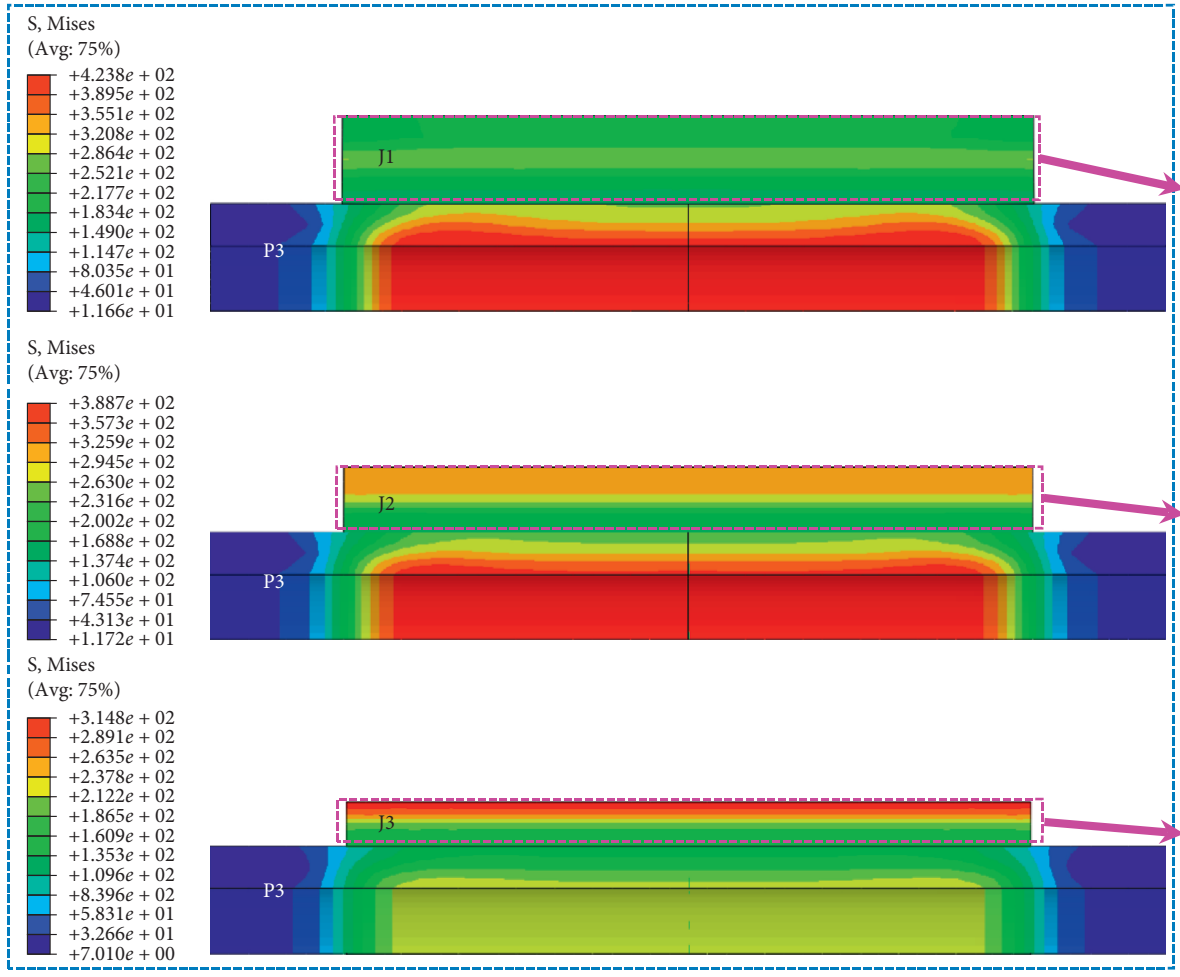

(a)

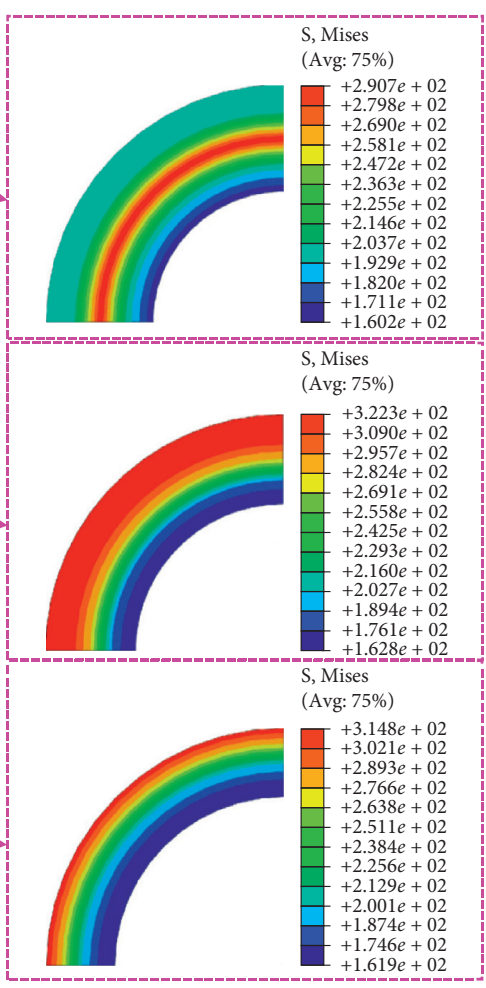

(b)

Figure 8: (a) Contour maps of $\sigma_{\text {equ }}$ in J1-P3, J2-P3, and J3-P3 at room temperature, and (b) Mises equivalent stress contour in the crosssection of the $\mathrm{NiTiNb}$ joint at room temperature.

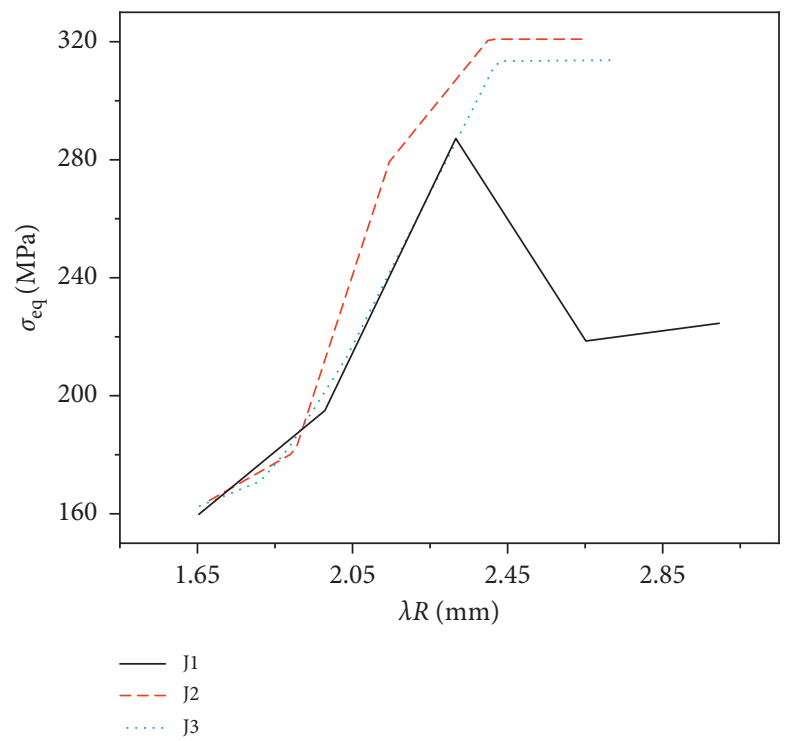

Figure 9: Distribution of $\sigma_{\mathrm{eq}}$ along the radial direction in the joint at room temperature.

end of the contact region, and the minimum $\sigma_{r}$ appears at $1 \mathrm{~mm}$ from the endpoint. For J2, the maximum $\sigma_{r}$ appears at the endpoint and central area. Such a pressure distribution is advantageous to the seal but is adverse to the effective work of the NiTiNb SMA joint, as the larger the contact pressure at the edge, the easier the destruction. For J1, maximal contact pressure appears at point $2 \mathrm{~mm}$ from the endpoint and minimal pressure appears at the endpoint of the contact region. This distribution can not only ensure a good seal but also benefit the effective work of the NiTiNb SMA joint. The thicker the joint wall, the larger the contact pressure. A thicker NiTiNb SMA joint would induce an enclasp force for a better seal effect, which is beneficial for the application of NiTiNb SMA joints.

As contact pressure is one of the key indicators of the pipe-joint systems, the change of contact pressure during the 


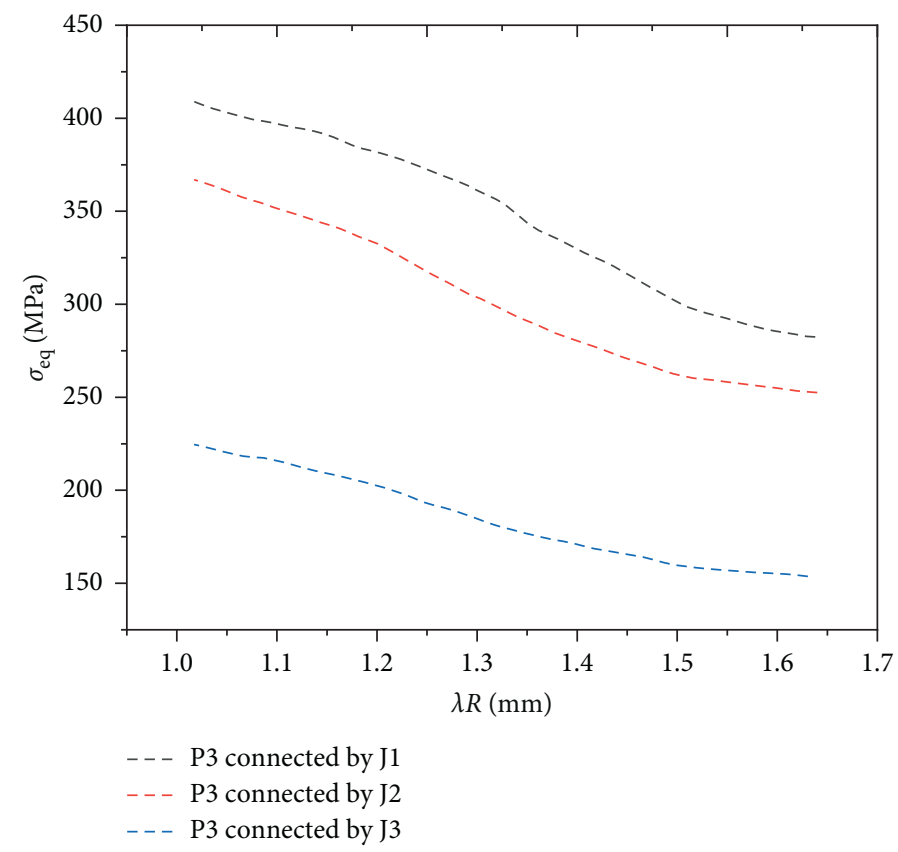

Figure 10: Distribution of $\sigma_{\text {eq }}$ along the radial direction in the steel pipe at room temperature.

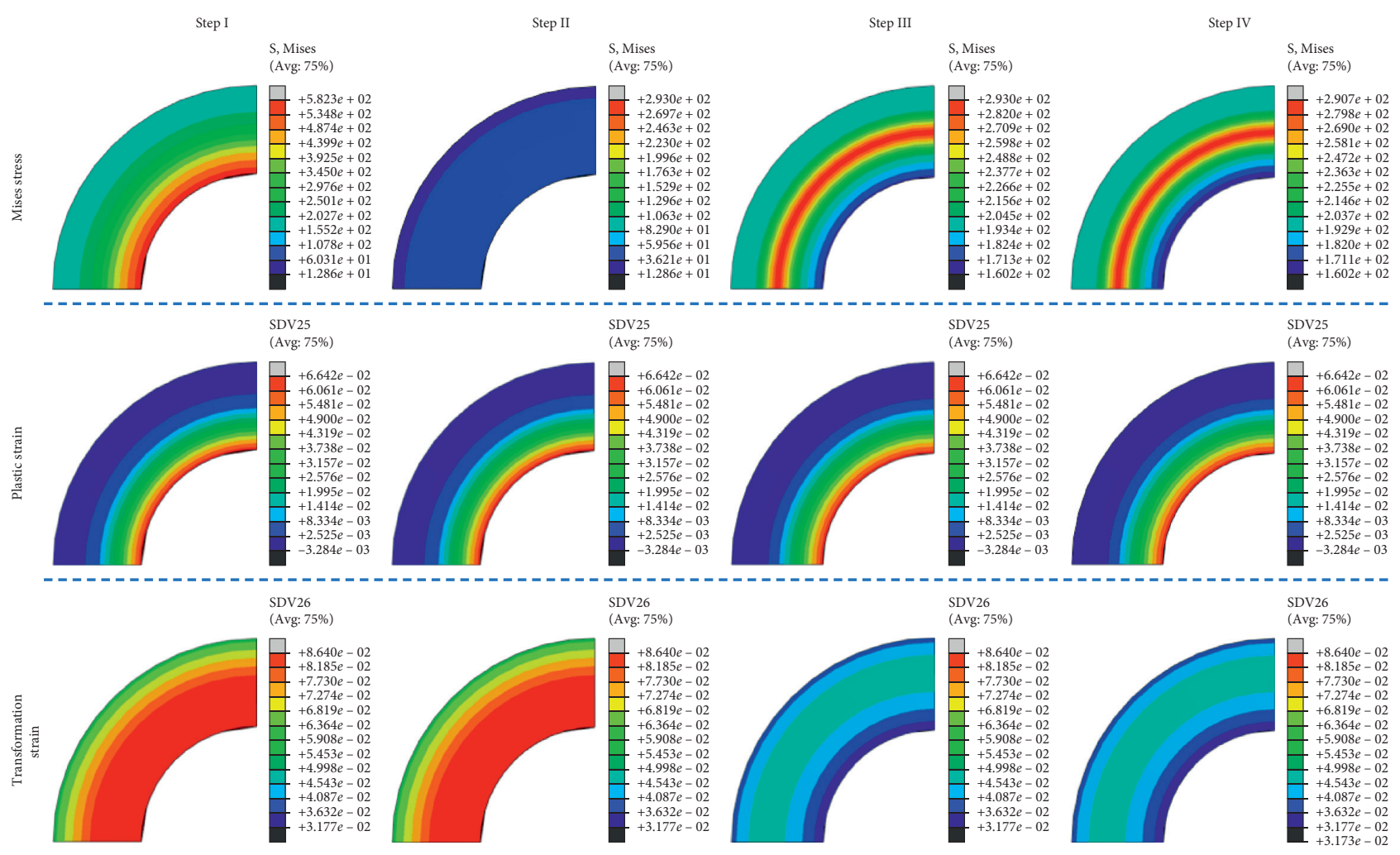

Figure 11: The distributions of von Mises stress, plastic strain, and transformation strain in different steps (J1-P3 system).

whole assembling process should be concerned. Figure 14 shows the variations of $\sigma_{r}$ at the pipe-joint interface (point $\mathrm{A}$ in Table 3) in the cases J1-P3, J2-P3, and J3-P3 (see Table 2) against $T$ during the assembling process. There is a similar tendency in the three kinds of joints: with the increase of $T$, $\sigma_{r}$ remains zero until $T$ increases to a certain value. This is because the SMA joint is not in contact with the steel pipe. Then $\sigma_{r}$ increases linearly with the increase of $T$ up to $T=100^{\circ} \mathrm{C}$, which is due to the combined action of thermal explanation and reverse phase transformation. In the following cooling process, Treduces from $100^{\circ} \mathrm{C}$ to $23^{\circ} \mathrm{C}$, a low decrease of $\sigma_{r}$ can be found. It is attributed to the different 

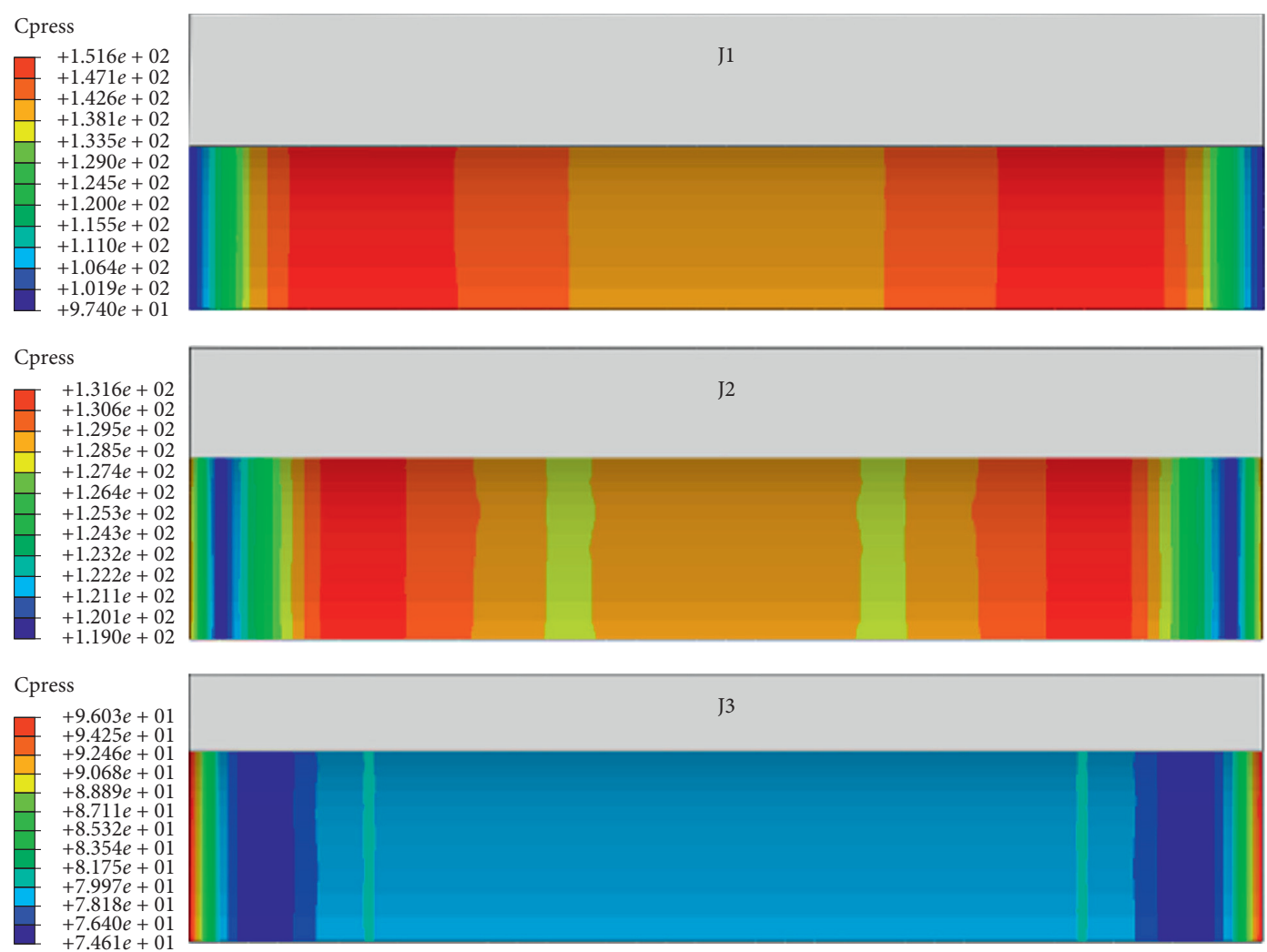

Figure 12: Contours map of pipe-joint interfacial pressures in $\mathrm{J} 1, \mathrm{~J} 2$, and $\mathrm{J} 3$ at room temperature.

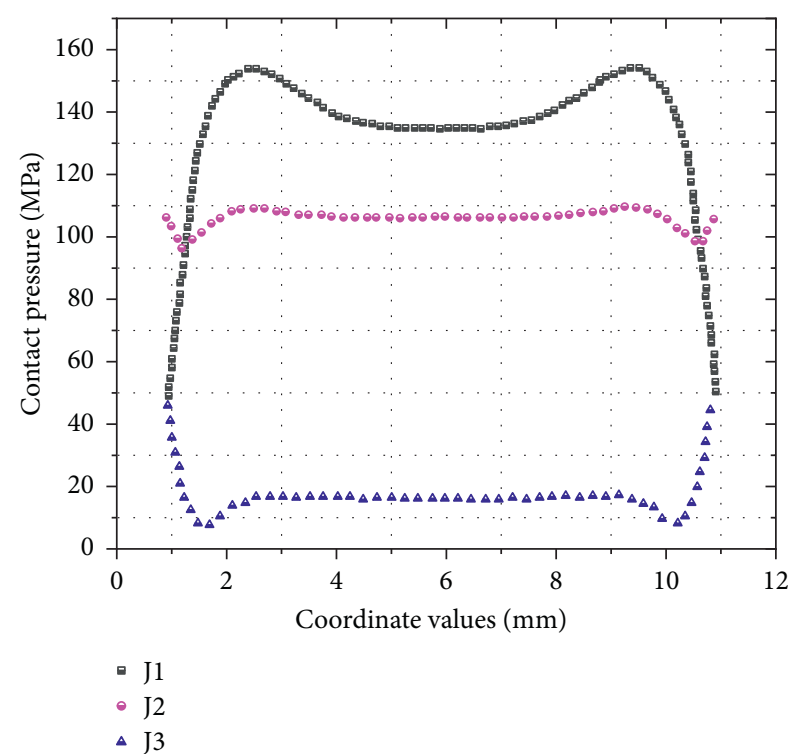

FIGURE 13: Longitudinal distributions of $\sigma_{r}$ in NiTiNb joints.

coefficients of thermal expansion of steel pipe and NiTiNb SMA joint. However, the following two main differences can also be found: (1) the temperatures for the onset of inverse transformation are different; i.e., they are about $22^{\circ} \mathrm{C}, 36^{\circ} \mathrm{C}$, and $53^{\circ} \mathrm{C}$ for J1-P3, J2-P3, and J3-P3, respectively; (2) the contact pressures after cooling to room temperature are different, that are about $143 \mathrm{MPa}, 126 \mathrm{MPa}$, and $80 \mathrm{MPa}$ for J1-P3, J2-P3, and J3-P3, respectively. The reason for the

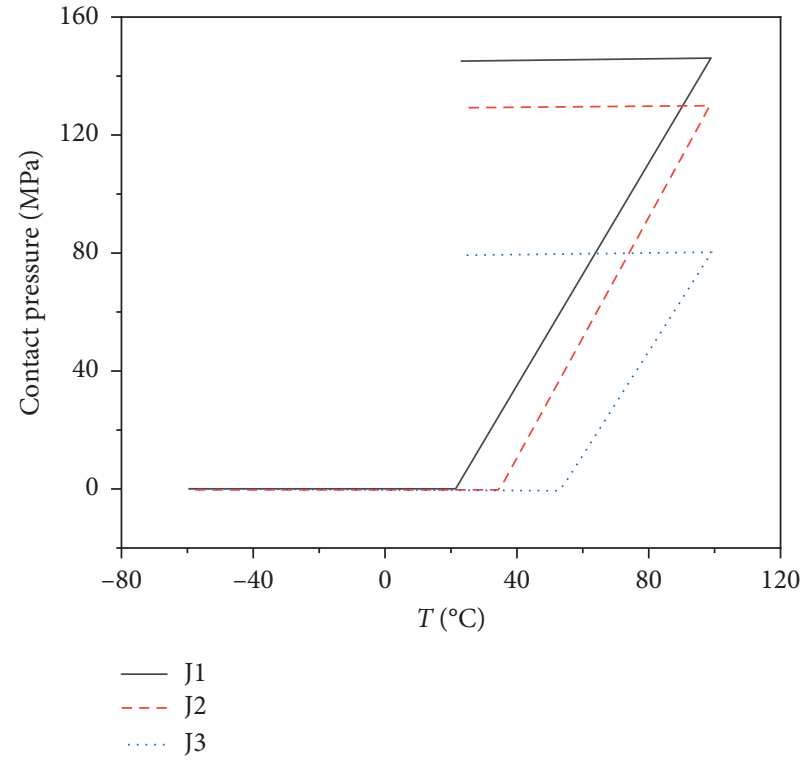

FIgURE 14: Variations of $\sigma_{\mathrm{r}}$ at the inner wall of different NiTiNb joints against $T$ during heating and cooling for $\mathrm{J} 1, \mathrm{~J} 2$, and $\mathrm{J} 3$.

differences is that for the same expansion deformation, the thinner the tube wall of the joint, the larger the plastic deformation in the joint. Plastic deformation that occurs during a prestrain process would relax the free energy stored in the material, leading to a higher temperature for the inverse transformation [20]. Therefore, the temperature for the onset of inverse transformation increases with the 
decrease of the joint thickness. Furthermore, the deformation in the radial direction is nonuniform; the plastic deformation near the inner wall is larger than that near the outer wall, as shown in Figure 11. During heating recovery, the plastic deformation region near the inner wall is subjected to pressure, which may counteract a part of the recovery force. The larger the plastic deformation is, the larger the recovery force would be counteracted, leading to the reduction of the final pressure from $\mathrm{J} 1$ to $\mathrm{J} 3$.

Figure 15 shows the variations of $\sigma_{r}$ at point A (see the FE model embed in Table 3) against $T$ during heating and cooling processes, in the case of P1 to P5 connected with J1 (see in Table 2). It can be seen that the curve of P1 is remarkably different from that of the others. The contact pressure of P1 is far less than the other four pipes. This difference is very important because the contact pressure directly determines the connection performance of the joint-pipe system. To explain this, the variation of the displacement at point A during stressfree heating after Step I is shown in Figure 16. The heating recovery curve agrees well with the experimental result (Figure 4(b)). In the initial stage, the displacement recovers slowly. The displacement recovers rapidly at near $20^{\circ} \mathrm{C}$ and then returns to the initial level. It is interesting to note that the reverse transformation temperatures are about $20^{\circ} \mathrm{C}$, which are below the $50^{\circ} \mathrm{C}$ in Figure 4(b). It can be attributed to the fact that the predeformation in the SMA joint is distributed in gradient while in the test sample, it is distributed uniformly. In Figure 16, the red arrows correspond to the positions of the outer wall of P1 to P5. It can be seen that for P2 to P5, the SMA joint contacts with the steel pipe during the rapid recovery segment, which may account for why the curves of $\mathrm{P} 2$ to $\mathrm{P} 5$ rise at near $20^{\circ} \mathrm{C}$, as shown in Figure 15. Instead, the SMA joint contact with $\mathrm{P} 1$ until the rapid reverse phase transformation is over, and the temperature rises to about $50^{\circ} \mathrm{C}$. It indicates that the main part of the heating should also occur at $T=20^{\circ} \mathrm{C}$, but before $T=50^{\circ} \mathrm{C}$ the recovery deformation is not sufficient to contact with the pipe. Thus, no $\sigma_{r}$ appears. As the joint contacts with the pipe at about $T=50^{\circ} \mathrm{C}, \sigma_{r}$ begins to increase. While the main part of the recoverable strain has already occurred, it accounts for the smaller $\sigma_{r}$ after recovery. At this point, the difference in Figure 15 is explained. From the result, it can be concluded that in order to obtain stable connection performance, the sizes of the SMA joint and the pipe shall be properly matched to ensure contact during the stage of the rapid reverse phase transformation.

3.4. Pull-Out Force. The pull-out process after assembling is performed at room temperature and the variation of the pull-out force $(F)$ against the pull-out displacement $(U)$ is shown in Figure 17 for J1-P3 system. In the beginning, the frictional resistance increases rapidly, mainly attributed to the static friction generated by contact pressure. The peak is $F \approx 1200 \mathrm{~N}$, which is close to the experimental results (between $1300 \mathrm{~N}$ and $2200 \mathrm{~N}$ ). The difference may result from the existence of the coating in the actual structure, which can not only improve leak tightness of the joint system but also enhances the joint strength by slowing down the stress concentration of the joint [29] and increases the frictional

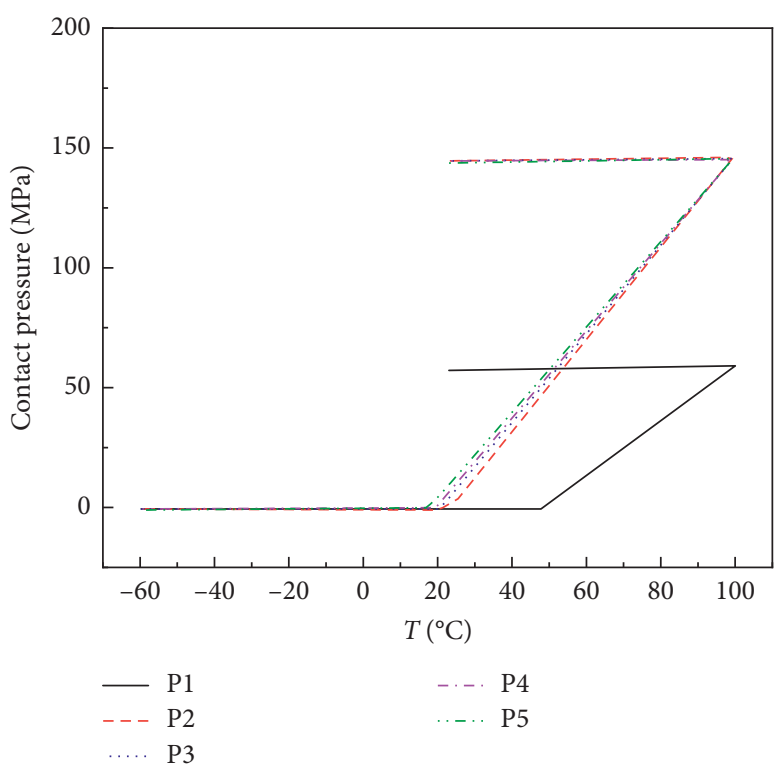

FIgURE 15: Variations of $\sigma_{r}$ at the inner wall (point A) of different $\mathrm{NiTiNb}$ joints against $T$ during heating and cooling for P1 through P5.

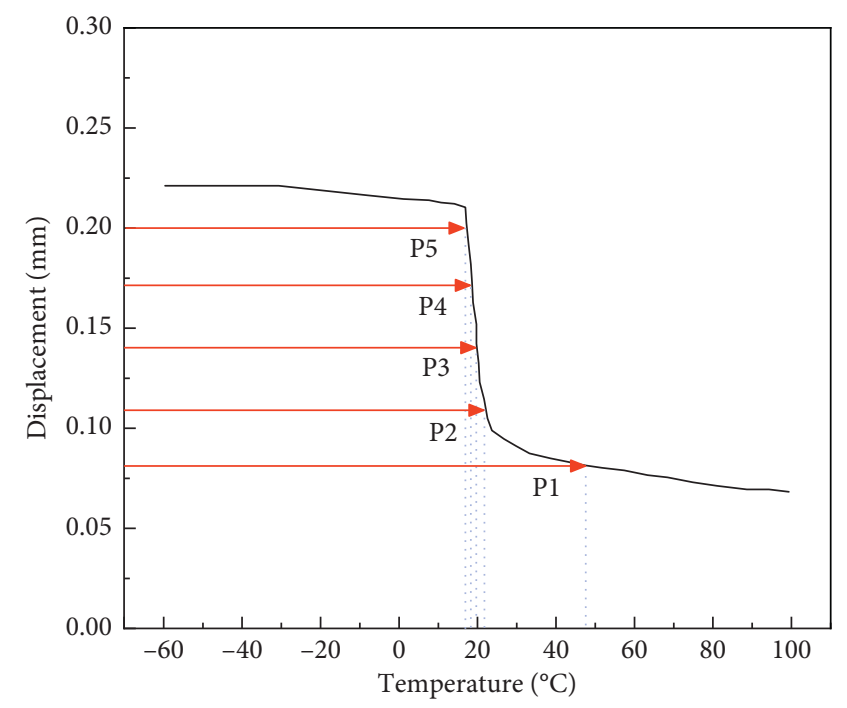

FIgURE 16: Variation of displacement at point $\mathrm{A}$ against temperature.

resistance. After the peak, $F$ decreases almost linearly with the increase of $U$, attributed to the decrease of the remaining contact area.

From the above results and analysis, one can find that the stress is inhomogeneous, whether in the joint, pipe, or on their contact surface. Thus employing traditional plane strain assumption or assuming the stress in joint and pipe as constant is inaccurate. A model that utilizes the FE method can compensate for the drawback. It can be obtained that the pull-out force increases with an increase of the NiTiNb SMA joint thickness; at the same time, the sealing property is also improved. Therefore, in the design process, some means 


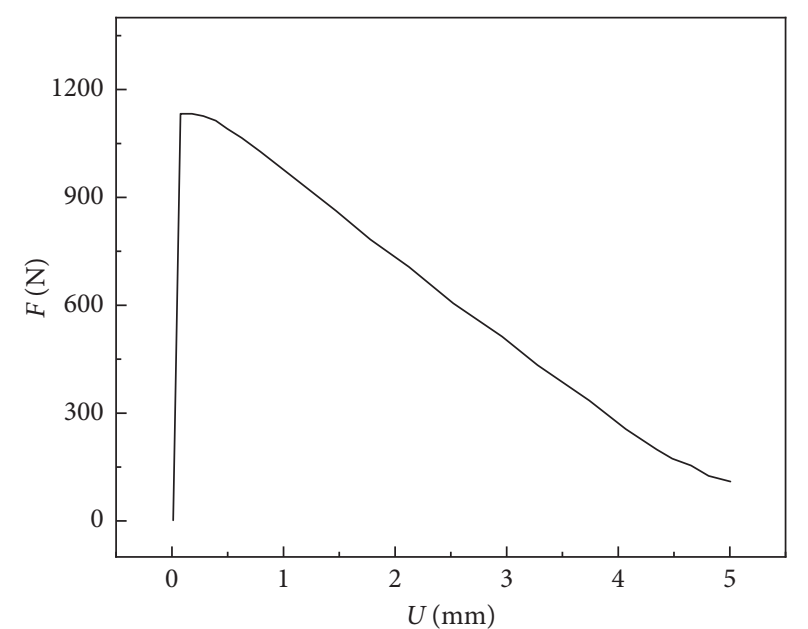

FIgURE 17: Variation of pull-out force against pull-out displacement.

such as reducing the joint diameter, increasing the wall thickness, and reducing the assembly clearance can be used to improve the contact pressure.

\section{Conclusions}

The assembling process of steel pipe-NiTiNb alloy joint systems was simulated with the FE approach, making use of a three-dimensional NiTiNb SMA model that takes into account coupled transformation and plastic deformation. The simulation includes the expansion of the cylindrical cavity at a low-temperature, heating and cooling of the pipe-joint system after assembling, and the following pullout process. Some conclusions can be drawn and listed as follows.

(1) After assembly, the Mises stress within the NiTiNb joint was closely related to the wall thickness of the joint. The maximum Mises equivalent stress did not appear at the inner wall of the joints, and the distribution was closely related to the coupling effects of plastic deformation and the recoverable transformation of the NiTiNb joint.

(2) The contact pressure uniformly distributed along ring direction but presented inhomogeneous distribution along the axial direction. The thicker the NiTiNb SMA joint wall, the larger the contact pressure. A thick NiTiNb SMA joint would provide a better seal effect and a larger enclasp force than a thin one.

(3) During the heating recovery, the contact pressure began to increase when a certain temperature was reached; then the contact pressure increased linearly and got its maximizing at $100^{\circ} \mathrm{C}$. In order to obtain stable connection performance, the sizes of the SMA joint and the pipe shall be properly matched to ensure contact during the stage of the rapid reverse phase transformation. The pull-out force reached its maximizing at the beginning and decreased linearly with the pull displacement.

\section{Data Availability}

The numerical data and pictures used to support the findings of this study are available from the corresponding author upon request.

\section{Conflicts of Interest}

The authors declare that they have no conflicts of interest.

\section{Acknowledgments}

The authors gratefully acknowledge the National Natural Science Foundation of China (Nos. 11802047, 11802045, and 11602042), the financial support to this work from the Open Fund of the State Key Laboratory (Nos.SKLMT-KFKT201711 and SV2018-KF-28), Chongqing Research Program of Basic Research and Frontier Technology (cstc2016jcyjA0594 and cstc2016jcyjA0443), and Dr. StartUp Fund of Chongqing University of Posts and Telecommunications (A2016-18).

\section{References}

[1] J. M. Jani, M. Leary, A. Subic, and M. A. Gibson, "A review of shape memory alloy research, applications and opportunities," Materials \& Design, vol. 56, no. 4, pp. 1078-1113, 2014.

[2] D. E. Hodgson, M. H. Wu, and R. J. Biermann, "Shape memory alloys," in ASM Handbook: Properties and Selection: Nonferrous Alloys and Special-Purpose, vol. 2, pp. 897-902, ASM International, Cleveland, OH, USA, 1990.

[3] W. Ochonski, "Application of shape memory materials in fluid sealing technology," Industrial Lubrication and Tribology, vol. 62, no. 2-3, pp. 99-110, 2010.

[4] X. Chen, X. Peng, B. Chen, J. Han, Z. Zeng, and N. Hu, "Experimental investigation to thermal-mechanical behavior of $\mathrm{Ni}_{47} \mathrm{Ti}_{44} \mathrm{Nb}_{9}$ SMA under pure tension and pure torsion," Journal of Alloys and Compounds, vol. 610, pp. 151-160, 2014.

[5] C. S. Zhang, Y. Q. Wang, W. Chai, and L. C. Zhao, "The study of constitutional phases in a $\mathrm{Ni}_{47} \mathrm{Ti}_{44} \mathrm{Nb}_{9}$ shape memory alloy," Materials Chemistry and Physics, vol. 28, no. 1, pp. 43-50, 1991.

[6] X. Y. Shu, S. Q. Lu, G. F. Li, J. W. Liu, and P. Peng, "Nb solution influencing on phase transformation temperature of $\mathrm{Ni}_{47} \mathrm{Ti}_{44} \mathrm{Nb}_{9}$ alloy," Journal of Alloys and Compounds, vol. 609, pp. 156-161, 2014.

[7] S. Jiang, Y. Liang, Y. Zhang, Y. Zhao, and C. Zhao, "Influence of addition of $\mathrm{Nb}$ on phase transformation, microstructure and mechanical properties of equiatomic NiTi SMA," Journal of Materials Engineering \& Performance, vol. 25, no. 10, pp. 4341-4351, 2016.

[8] X. Chen, X. H. Peng, B. Chen, J. Han, Z. M. Zeng, and N. Hu, "Experimental investigation on transformation, reorientation and plasticity of $\mathrm{Ni}_{47} \mathrm{Ti}_{44} \mathrm{Nb}_{9}$ SMA under biaxial thermalmechanical loading," Smart Materials and Structures, vol. 24, no. 7, 2015.

[9] P. C. Jiang, Y. F. Zheng, Y. X. Tong et al., "Transformation hysteresis and shape memory effect of an ultrafine-grained TiNiNb shape memory alloy," Intermetallics, vol. 54, pp. 133-135, 2014.

[10] K. Uchida, N. Shigenaka, T. Sakuma, Y. Sutou, and K. Yamauchi, "Effects of pre-strain and heat treatment temperature on phase transformation temperature and shape 
recovery stress of $\mathrm{Ti}-\mathrm{Ni}-\mathrm{Nb}$ shape memory alloys for pipe joint applications," Materials Transactions, vol. 49, no. 7, pp. 1650-1655, 2008.

[11] C. Ying, J. Hai-chang, R. Li-jian, X. Li, and Z. Xin-qing, "Mechanical behavior in NiTiNb shape memory alloys with low $\mathrm{Nb}$ content," Intermetallics, vol. 19, no. 2, pp. 217-220, 2011.

[12] G. Urbikain, J. M. Perez, L. N. López de Lacalle, and A. Andueza, "Combination of friction drilling and form tapping processes on dissimilar materials for making nutless joints," Proceedings of the Institution of Mechanical Engineers, Part B: Journal of Engineering Manufacture, vol. 232, no. 6, pp. 1007-1020, 2016.

[13] L. Zhou, K. Nakata, T. Tsumura et al., "Microstructure and mechanical properties of 316L stainless steel filling friction stir-welded joints," Journal of Materials Engineering and Performance, vol. 23, no. 10, pp. 3718-3726, 2014.

[14] A. Suárez, F. Veiga, L. N. L. de Lacalle, R. Polvorosa, S. Lutze, and A. Wretland, "Effects of ultrasonics-assisted face milling on surface integrity and fatigue life of Ni-alloy 718," Journal of Materials Engineering and Performance, vol. 25, no. 11, pp. 5076-5086, 2016.

[15] M. Tabesh, K. C. Atli, J. Rohmer et al., "Design of shape memory alloy pipe couplers: modeling and experiments," Industrial and Commercial Applications of Smart Structures Technologies, vol. 2012, 2012.

[16] L. G. Machado and D. C. Lagoudas, Thermomechanical Constitutive Modeling of SMAs, Springer, Berlin, Germany, 2008.

[17] G. L. Yang, Z. M. Ni, J. Han, and E. M. Wang, "Simulation on pipe joints expansion technology of NiTiNb shape memory alloy," Advanced Materials Research, vol. 189-193, pp. 1711-1717, 2011.

[18] B. Piotrowski, T. B. Zineb, E. Patoor, and A. Eberhardt, "Experimental and numerical analysis of recovery stress in $\mathrm{Ni}_{47} \mathrm{Ti}_{44} \mathrm{Nb}_{9}$ shape memory alloys: application to tightening," Physics Procedia, vol. 10, pp. 204-209, 2010.

[19] B. Piotrowski, T. Ben Zineb, E. Patoor, and A. Eberhardt, "A finite element-based numerical tool for $\mathrm{Ni}_{47} \mathrm{Ti}_{44} \mathrm{Nb}_{9}$ SMA structures design: application to tightening rings," Journal of Intelligent Material Systems and Structures, vol. 23, no. 2, pp. 141-153, 2012.

[20] M. Piao, K. Otsuka, S. Miyazaki, and H. Horikawa, "Mechanism of the $A_{s}$ temperature increase by pre-deformation in thermoelastic alloys," Materials Transactions, JIM, vol. 34, no. 10, pp. 919-929, 1993.

[21] M. A. Qidwai and D. C. Lagoudas, "Numerical implementation of a shape memory alloy thermomechanical constitutive model using return mapping algorithms," International Journal for Numerical Methods in Engineering, vol. 47, no. 6, pp. 1123-1168, 2015.

[22] C. Yu, G. Kang, and Q. Kan, “A micromechanical constitutive model for anisotropic cyclic deformation of super-elastic NiTi shape memory alloy single crystals," Journal of the Mechanics \& Physics of Solids, vol. 82, pp. 97-136, 2015.

[23] M. Barati, G. Helbert, L. Saint-Sulpice, M. Kadkhodaei, S. A. Chirani, and S. Calloch, "A three-dimensional macroscopic fully thermomechanically coupled constitutive model for shape memory alloy under thermomechanical cyclic loading," in The 21st European Conference on Fracture, ECF21, Catania, Italy, June 2016.

[24] B. Chen, X. Peng, X. Chen, J. Wang, H. Wang, and N. Hu, "A three-dimensional model of shape memory alloys under coupled transformation and plastic deformation," $C M C$ -
Computers Materials \& Continua, vol. 30, no. 2, pp. 145-176, 2012.

[25] C. S. Zhang, L. C. Zhao, T. W. Duerig, and C. M. Wayman, "Effects of deformation on the transformation hysteresis and shape memory effect in a $\mathrm{Ni}_{47} \mathrm{Ti}_{44} \mathrm{Nb}_{9}$ alloy," Scripta Metallurgica et Materialia, vol. 24, no. 9, pp. 1807-1812, 1990.

[26] D. M. Krahmer, R. Polvorosa, L. N. L. D. Lacalle, U. AlonsoPinillos, G. Abate, and F. Riu, "Alternatives for specimen manufacturing in tensile testing of steel plates," Experimental Techniques, vol. 40, no. 6, pp. 1555-1585, 2016.

[27] A. C. Souza, E. N. Mamiya, and N. Zouain, "Three-dimensional model for solids undergoing stress-induced phase transformations," European Journal of Mechanics-A/Solids, vol. 17, no. 5, pp. 789-806, 1998.

[28] M. Frémond and B. Nedjar, "Damage, gradient of damage and principle of virtual power," International Journal of Solids \& Structures, vol. 33, no. 8, pp. 1083-1103, 1996.

[29] X. F. Zhou, Y. H. Zhi, and B. W. Gou, "Finite element analysis of creep and thermal stress for shape memory alloy joint," Key Engineering Materials, vol. 452-453, pp. 537-540, 2011. 